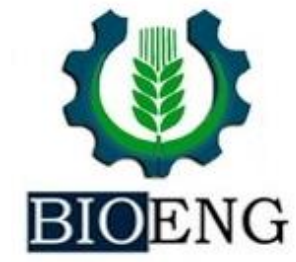

\title{
DIAGNÓSTICO DA EXIGÊNCIA DO ALGODOEIRO EM NITROGÊNIO E NÍQUEL PELA UTILIZAÇÃO DO MEDIDOR PORTÁTIL DE CLOROFILA
}

J. P. Q. Barcelos ${ }^{1 *}$, E. Furlani Junior ${ }^{1}$, H. P. G. Reis ${ }^{1}$, F. F. Putti ${ }^{2}$, A. R. dos Reis ${ }^{2}$

${ }^{1}$ UNESP - Univ Estadual Paulista, FEIS - Faculdade de Engenharia de Ilha Solteira, Ilha Solteira, SP, Brasil.

${ }^{2}$ UNESP - Univ Estadual Paulista, FCA - Faculdade de Ciências e Engenharia, Tupã, SP, Brasil.

Article history: Received 19 January 2016; Received in revised form 08 March 2016; Accepted 10 March 2016; Available online 21 March 2016.

\section{RESUMO}

O nitrogênio é o nutriente mais absorvido pelo algodoeiro, sendo que uma das principais formas de armazenamento nas plantas envolve ureídeos e arginina, o que torna o níquel (componente da metaloenzima urease) essencial para o metabolismo e eficiência da utilização do nitrogênio pelo algodoeiro. Dessa forma o presente trabalho teve por objetivo avaliar a resposta do algodoeiro FMT-701 submetido a doses combinadas de nitrogênio e níquel. O experimento foi desenvolvido em condições de casa de vegetação, sendo conduzido em vasos de $5 \mathrm{dm}^{-3}$ contendo Latossolo Vermelho Distrófico. Foi utilizado o delineamento de blocos inteiramente casualizado disposto em esquema fatorial 4 x 4 , sendo 4 doses de nitrogênio $\left(0,40,80\right.$, e $\left.120 \mathrm{~kg} \mathrm{ha}^{-1}\right)$ e 4 doses de níquel $\left(0,50,150\right.$, e $\left.300 \mathrm{~g} \mathrm{ha}^{-1}\right)$, totalizando 16 tratamentos em triplicata. O índice SPAD de clorofila foi monitorado aos 1, 2, 8, 16, 24, 32, 40 e 48 dias após a aplicação da ureia. O níquel não apresentou nenhum efeito no aumento no índice de clorofila. Por outro lado, o efeito da aplicação de ureia no índice de clorofila foi significativo aos 40 e 48 dias após a aplicação. O intervalo entre 45 a $90 \mathrm{~kg} \mathrm{ha}^{-1}$ de nitrogênio proporcionou maiores leituras de clorofila, sendo que as doses de níquel não influenciaram no índice de clorofila. Assim, pode-se inferir que não é necessário a aplicação de doses acima de $60 \mathrm{~kg} \mathrm{ha}^{-1}$ de nitrogênio, o que significa uma economia de fertilizante nitrogenado. $\mathrm{O}$ índice de clorofila correlacionou-se positivamente com o teor de nitrogênio nas folhas, mas não com os teores foliares de níquel. O índice clorofila aumentou ao longo do ciclo da cultura independente dos tratamentos. A estimativa do teor de clorofila foi promissora para detecção de possíveis deficiências de nitrogênio em plantas de algodão.

Palavras-chave: adubação nitrogenada, urease, micronutriente

\section{DIAGNOSIS OF NITROGEN AND NICKEL REQUIREMENTS FOR COTTON PLANTS USING A PORTABLE CHLOROPHYLL METER}

\begin{abstract}
Nitrogen is the most required nutrient by cotton plants, and its storage form in plants involves ureides and arginine, which makes nickel (component metalloenzyme urease) essential for metabolism and efficiency of nitrogen utilization by cotton plants. This study aimed to evaluate the response of cotton cv. FMT-701 due to combination of nitrogen and

\footnotetext{
* jessica.pqb@gmail.com
} 
nickel application. The experiment was carried out under greenhouse conditions using pots containing $5 \mathrm{dm}^{-3}$ of Oxisoil distrofic. The experiment was conducted on an entirely randomized design and a factorial scheme $4 \times 4$; where 4 levels of nitrogen $(0,40,80$, and 120 $\mathrm{kg} \mathrm{ha}^{-1}$ ) and 4 levels of nickel $\left(0,50,150\right.$ and $\left.300 \mathrm{~g} \mathrm{ha}^{-1}\right)$, totaling 16 treatments with 3 replications. The chlorophyll was monitored at 1, 2, 8, 16, 24, 32, 40 and 48 days after application (DAA) of urea. Levels of nickel show no effect on chlorophyll index. On the other hand, the application of urea showed a significant increase on chlorophyll index especially during 40 and 48 DAA. The same effect was not found for nickel application. The range between 45 and $90 \mathrm{~kg} \mathrm{ha}^{-1}$ of nitrogen resulted in higher chlorophyll index. Thus, our results suggest that it is not necessary to apply levels of nitrogen above $60 \mathrm{~kg} \mathrm{ha}^{-1}$, which means a great economy on nitrogen fertilizer application to cotton plants. The chlorophyll index was highly positively correlated to leaf nitrogen concentration but no relationship was found to foliar nickel concentration. The chlorophyll index increased in cotton leaves during development stage in all treatments. The use of portable chlorophyll meter to evaluate the nitrogen status requirement is a promising tool to detect possible nitrogen deficiency in cotton plants.

Keywords: nitrogen fertilizer, urease, micronutrient.

\section{INTRODUÇÃO}

O algodoeiro é a planta de aproveitamento mais completo e a que oferece a mais variada gama de produtos de utilização universal, sendo considerada a mais importante das fibras têxteis, levando em conta o volume da produção e o valor monetário de sua cadeia produtiva (MAO et al., 2015).

$\mathrm{O}$ nitrogênio é o nutriente mais requerido pela planta de algodão. $\mathrm{O}$ algodoeiro apresenta uma grande limitação interna no metabolismo do nitrogênio, em função da competição que estabelece entre a redução de $\mathrm{CO}_{2}$ e a do nitrato (STAMATIADIS et al., 2016). Assim, para que ocorra o máximo de fotossíntese, o algodoeiro, planta com metabolismo $\mathrm{C}_{3}$, necessita 2 vezes mais nitrogênio nas folhas do que espécies de ciclo $\mathrm{C}_{4}$ (SALEEM et al., 2016). Com o surgimento da agricultura de precisão, dentre outras finalidades, está sendo proposta como uma nova filosofia de manejo dos cultivos que poderá contribuir para a diminuição da sub ou superutilização de fertilizantes nitrogenados. Trata-se de uma tecnologia de informação que possibilita o gerenciamento da atividade agrícola levando-se em consideração a variabilidade espacial e temporal do solo e da cultura, permitindo desta forma a otimização de recursos do ambiente e o uso racional de insumos agrícolas (CETIN et al., 2015).

O medidor portátil de clorofila que faz leituras instantâneas sem necessidades de destruição da folha, surge como nova ferramenta para avaliar o nível de nitrogênio na planta (REIS et al. 2015). As leituras efetuadas por este equipamento indicam valores proporcionais de clorofila na folha e são calculadas com base na quantidade de luz transmitida pela folha em dois comprimentos de ondas com distintos absorbâncias de clorofila (BRITO et al., 2011). A utilização do parâmetro teor de clorofila, apresenta grande potencial como indicador para a recomendação de adubação nitrogenada para o algodoeiro, principalmente se associado a indicadores de solo (ROSOLÉM e van MELLIS, 2010; MOTOMIYA et al., 2014).

A ureia é o principal fertilizante sólido no mercado mundial, sendo que no Brasil, este produto responde por cerca de $60 \%$ dos fertilizantes nitrogenados comercializados (REIS et al., 2014). Além disso, a ureia também pode ser sintetizada pelas plantas, originando-se do passo terminal do ciclo da ornitina catalisada pela arginase mitocondrial, que envolve a 
hidrólise de arginina para ornitina e ureia (FABIANO et al., 2015; TEZOTTO et al., 2016).

O níquel é um elemento constituinte da metaloenzima urease, enzima que catalisa a degradação da ureia em dióxido de carbono $\left(\mathrm{CO}_{2}\right)$ e amônia $\left(\mathrm{NH}_{3}\right)$, o que o torna extremamente importante para o metabolismo do nitrogênio nas plantas, podendo aumentar a eficiência e a produtividade das culturas (POLACCO et al., 2013; RODAK, 2014). Entretanto, quando absorvido em grandes quantidades o níquel apresenta efeito

\section{MATERIAL E MÉTODOS}

\section{Localização do experimento}

O presente trabalho foi instalado na Casa de Vegetação do Departamento de Fitotecnia, Tecnologia de Alimentos e Sócio-Economia da UNESP/Ilha Solteira. O solo foi classificado como Latossolo Vermelho Distrófico típico muito argiloso, tóxico para as mesmas, sendo considerado um metal pesado.

$\mathrm{O}$ presente trabalho teve por objetivo avaliar a exigência nutricional de nitrogênio e níquel do algodoeiro em estágio inicial de crescimento utilizando o medidor portátil de clorofila. A hipótese do trabalho é o níquel atuando no desvio de rota do metabolismo do nitrogênio pelo aumento do índice de clorofila e consequentemente aumento na eficiência no uso do nitrogênio e redução da aplicação de fertilizantes nitrogenados na cultura do algodoeiro.

Tabela 1. Características químicas do solo antes da instalação do experimento

\begin{tabular}{|c|c|c|c|c|c|c|c|c|c|}
\hline \multirow{2}{*}{$P_{\text {resina }}{\mathrm{mg} / \mathrm{dm}^{3}}^{3}$} & \multirow{2}{*}{$\begin{array}{l}\text { M.O. } \\
\text { g/dm }\end{array}$} & \multirow{2}{*}{$\begin{array}{c}\mathbf{p H} \\
\left(\mathrm{CaCl}_{2}\right)\end{array}$} & $K$ & $\mathbf{C a}$ & Mg & $\mathrm{H}+\mathrm{Al}$ & Al & CTC & \multirow{2}{*}{$\begin{array}{c}\mathrm{V} \\
(\%)\end{array}$} \\
\hline & & & \multicolumn{6}{|c|}{$\mathrm{mmol}_{\mathrm{c}} / \mathrm{dm}^{3}$} & \\
\hline 7 & 23 & 4,7 & 2,0 & 19 & 10 & 38 & 2 & 69,0 & 45 \\
\hline B & $\mathbf{C u}$ & Fe & \multicolumn{3}{|c|}{ Mn } & $\mathbf{Z r}$ & \multicolumn{3}{|c|}{$\mathbf{N i}$} \\
\hline \multicolumn{10}{|c|}{$\mathrm{mg} / \mathrm{dm}^{3}$} \\
\hline 0,15 & 1,6 & 55 & & 27 & & 1,2 & & & \\
\hline
\end{tabular}

O experimento foi instalado no delineamento inteiramente casualizado disposto em esquema fatorial $4 \times 4$, sendo 4 doses de nitrogênio $(0,40,80$, e $120 \mathrm{~kg}$ $\left.\mathrm{ha}^{-1}\right)$ e 4 doses de níquel $(0,50,150$, e 300 $\mathrm{g} \mathrm{ha}^{-1}$ ), constituindo 16 tratamentos em triplicata, totalizando 48 vasos.

Para realizar a adubação nitrogenada, a ureia foi pesada e distribuída manualmente em cada parcela. Para a adubação com níquel, o sulfato de níquel foi pesado, e devido a sua pequena quantidade, foi diluído em água deionizada antes de ser aplicado no solo para facilitar sua distribuição nas parcelas experimentais. Cada parcela experimental foi composta por um vaso, com capacidade para $5 \mathrm{dm}^{-3}$ de solo, onde foram semeadas conforme classificação brasileira dos solos (EMBRAPA, 2006). Foi realizada amostragem de solo para caracterização das propriedades químicas seguindo a metodologia de análise descrita por Raij \& Quaggio (2001), cujos resultados são apresentados na Tabela 01. 


\section{Variáveis analisadas}

Índice de clorofila

$\mathrm{O}$ índice de clorofila foi medido com auxílio do medidor de clorofila portátil modelo SPAD-502, desenvolvido pela MINOLTA (1989), realizadas na terceira folha do ápice para a base do algodoeiro. Foram realizadas avaliações no dia da adubação, antes de realizar o tratamento, 24 horas após a adubação, 2, 8, 16, 24, 32, 40 e 48 dias após a aplicação da ureia.

\section{Análise nutricional}

No final do experimento (85 dias após a emergência) foram coletadas todas as folhas de cada planta e colocadas em sacos de papel previamente tarados e identificados, e, em seguida, foram colocadas para secar em estufa à $60^{\circ} \mathrm{C}$ por 48 horas. Após atingir massa constante, as folhas foram moídas em moinhos tipo Willey e armazenadas em sacos plásticos até o momento da análise. Para a análise do teor foliar de níquel a amostra foi digerida em solução nitro-perclórica e analisada em espectrometria de absorção atômica. $\mathrm{O}$ teor de nitrogênio total foi determinado pela

\section{RESULTADOS E DISCUSSÃO}

O nitrogênio é um dos elementos minerais mais requeridos em maior quantidade pelas plantas e o que mais limita o crescimento (REIS et al., 2015). Ele faz parte de proteínas, ácidos nucléicos e muitos outros importantes constituintes celulares, incluindo membranas e diversos hormônios vegetais. Sua deficiência resulta em clorose gradual das folhas mais velhas e redução do crescimento da planta, pois é constituinte da molécula de clorofila, a qual é responsável pela captação de luz solar e consequentemente pela atividade fotossintética das plantas (TEZOTTO et al., 2015). No presente estudo, o índice SPAD apresentou uma função quadrática em resposta a aplicação de doses de nitrogênio como indicado na Figura 1(A). $\mathrm{O}$ índice de clorofila diminuiu drasticamente a partir da dose $90 \mathrm{~kg} \mathrm{ha}^{-1} \mathrm{de}$ nitrogênio. Foi avaliado o índice SPAD aos $1,2,8,16,24,32,40$ e 48 DAA, porém digestão sulfúrica e destilação Kjeldhal (MALAVOLTA et al., 1997).

\section{Análise dos dados}

Para a verificar o efeito das doses de nitrogênio e níquel, foi realizado previamente a análise de normalidade dos dados. Deste modo, utilizou-se o modelo estatístico abaixo:

$$
\begin{gathered}
Y(N i, N)=b_{0}+b_{1} \cdot N+b_{11} N^{2}+b_{2} N i+ \\
b_{22} N I^{2}+N N i
\end{gathered}
$$

$Y(W, N)$ - fator do Índice SPAD, em função das doses de nitrogênio e níquel.

$N$ - doses de nitrogênio, $\mathrm{kg} / \mathrm{ha}$;

$\mathrm{Ni}$ - doses de níquel, g/ha;

$b_{0}, b_{1}, b_{2}, b_{11}, b_{22} e b_{12}$ - parâmetros da função.

De acordo com a equação 1 foi calculado as superfícies de resposta e o mapa de contorno para o índice SPAD. Foi aplicado a análise de correlação de Pearson para teste de correlação entre o teor de nitrogênio e níquel foliar com o índice SPAD bem como regressões quadráticas para curva de resposta do índice SPAD em função das doses de nitrogênio aplicado.

somente apartir dos 40 DAA foi estatisticamente significativo a resposta da clorofila em função da aplicação do nitrogênio. $O$ nitrogênio assimilado foi incorporado a moléculas de clorofila tornando as folhas do algodoeiro mais verdes refletindo no índice SPAD. (MOTOMIYA et al., 2014). De acordo com a Figura 1(B), a maior tonalidade de verde representa os maiores índices SPAD que variam na faixa de 40 a $90 \mathrm{~kg} \mathrm{ha}^{-1} \mathrm{de}$ nitrogênio. 
(A)

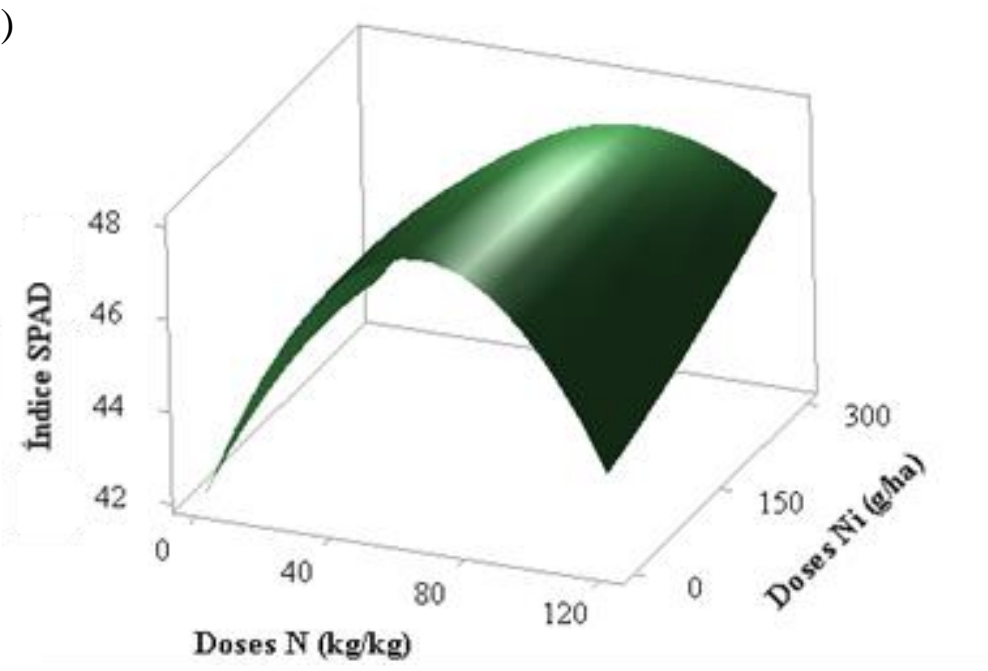

(B)

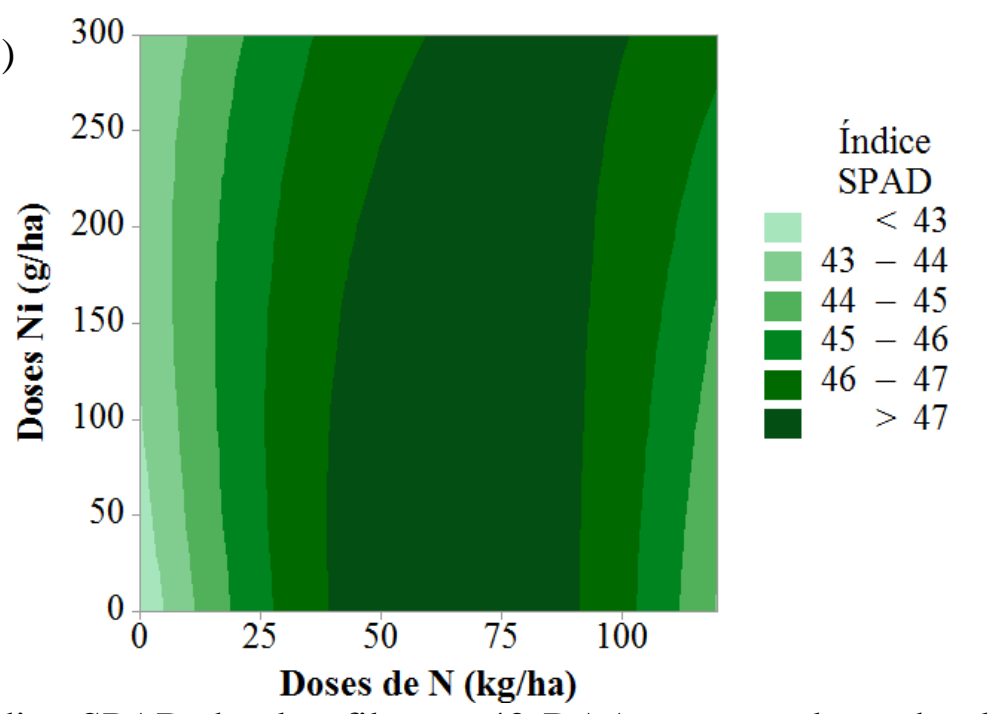

Figura 1. Índice SPAD de clorofila aos 40 DAA para a cultura do algodão submetido em diferentes doses de nitrogênio e níquel. (A) Superfície de resposta e (B) Mapa de contorno.

Resultados similares em relação ao índice SPAD foram observados para curvas de resposta ao nitrogênio e níquel em algodoeiro aos 48 DAA. O níquel não influenciou significativamente no aumento dos índices SPAD de clorofila (Figura 2(A)).
No entanto, o intervalo das doses de nitrogênio que proporcionaram maiores valores SPAD variou de 48 a $100 \mathrm{~kg} \mathrm{ha}^{-1}$ como indicado no mapa de contorno (Figura 2(B)). 
(A)

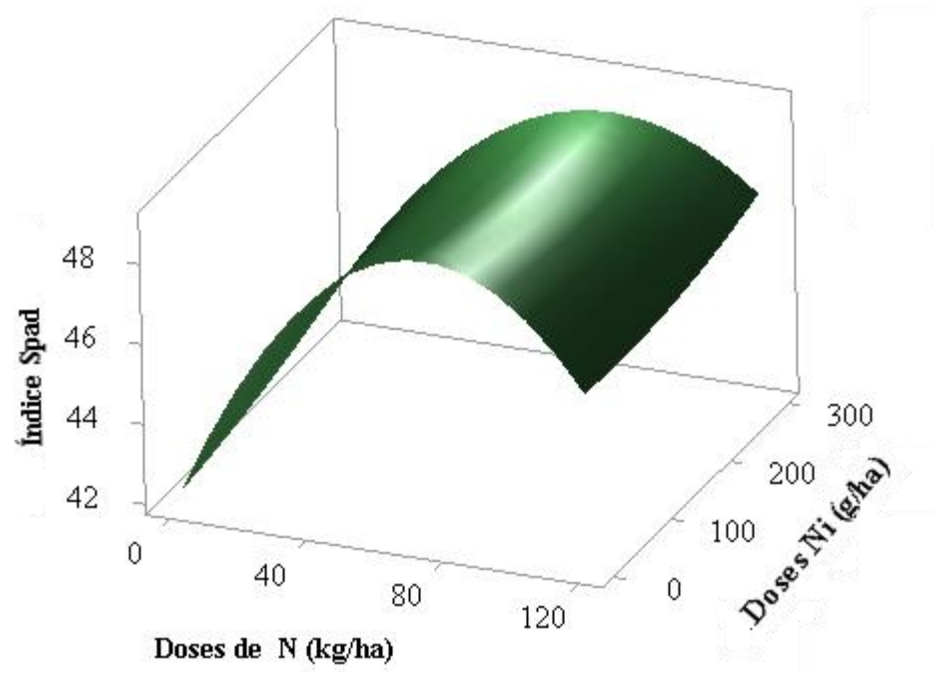

(B)

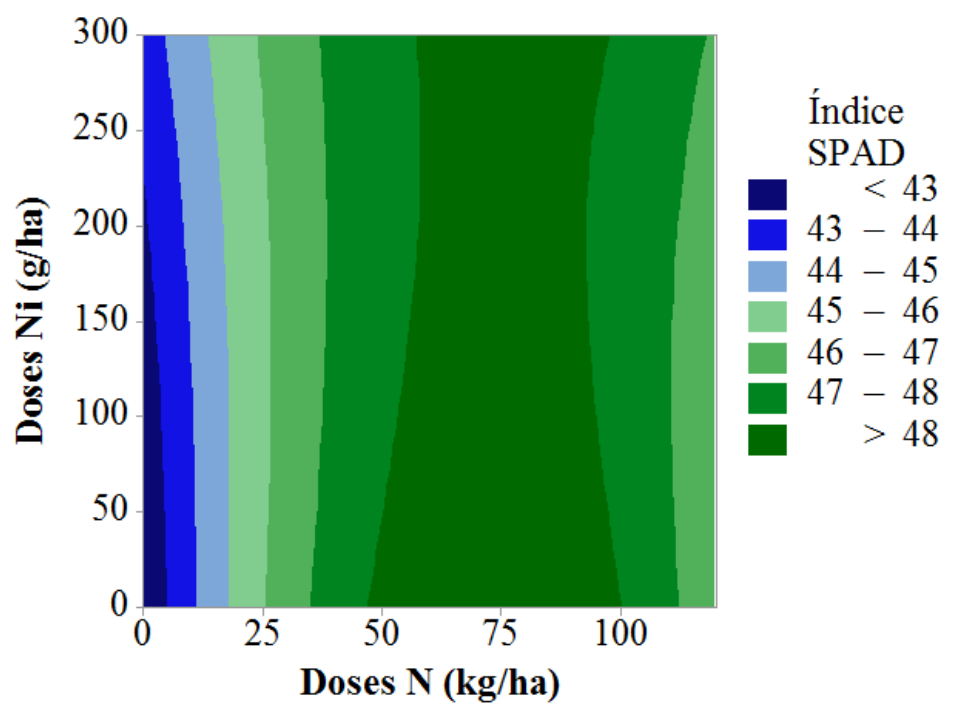

Figura 2. Índice SPAD aos 48 DAA para a cultura do algodão submetido em diferentes doses de nitrogênio e níquel (A) Superfície de resposta e (B) Mapa de contorno.

Motomiya et al. (2014), também obteve uma relação quadrática e significativa para as doses de nitrogênio e para o índice SPAD, com decréscimo para a dose de $150 \mathrm{~kg} \mathrm{ha}^{-1}$ de $\mathrm{N}$ e ponto máximo para a dose de $53,75 \mathrm{~kg} \mathrm{ha}^{-1}$ de nitrogênio em cobertura.

Conforme destacaram Rosolem e Van Mellis (2010), o medidor de clorofila pode ser usado na estimativa do estado nutricional do algodoeiro a partir da terceira semana de florescimento, o que pode explicar $o$ efeito significativo observado apenas a partir da $6^{\mathrm{a}}$ avaliação.

As médias referentes a massa seca total de folhas (dados não apresentados), não apresentaram resultado significativo para os tratamentos com níquel e a interação entre nitrogênio e níquel. Para nitrogênio houve efeito significativo, sendo que houve aumento linear da massa seca acompanhando as doses crescentes de nitrogênio. Para as médias referentes a área foliar total não houve efeito significativo para nenhum dos tratamentos analisados. Rosa (2012), estudando a resposta do algodoeiro a diferentes doses de nitrogênio, também observou aumento da massa seca em algodoeiro até a dose de $100 \mathrm{~kg} \mathrm{ha}^{-1}$, com um decréscimo para esse parâmetro com dosagens acima de $200 \mathrm{~kg}$ $\mathrm{ha}^{-1} \mathrm{de} \mathrm{N}$.

Independente da data de avaliação (40 ou 48 DAA), a correlação entre o 
índice SPAD de clorofila e os teores foliares de nitrogênio foram altamente significativos, sendo $\mathrm{R}^{2}=0.46(\mathrm{p}<0.001)$ para 40 DAA e $\mathrm{R}^{2}=0.51(\mathrm{p}<0.001)$ para 48 DAA (Figura 3), respectivamente. Não houve correlação significativamente positiva entre os teores foliares de níquel e índice SPAD (dados não apresentados). Tal fato se deve a não participação do níquel na síntese de clorofila e sim na hidrólise da ureia, transformando-a em amônia e gás carbônico (RODAK, 2014).

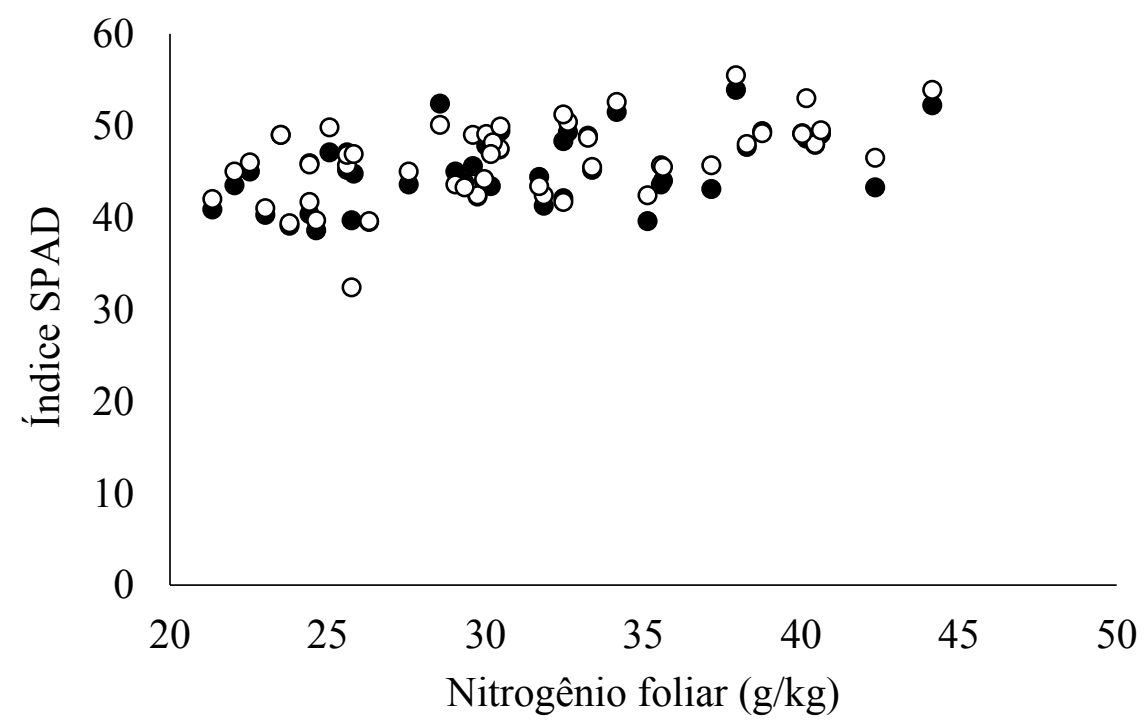

Figura 3. Correlação entre os teores foliares de nitrogênio e índice SPAD para a cultura do algodão. Sendo, $(\bullet)-40$ DAA e (०) - 48 DAA.

Os índices SPAD aumentaram em função dos dias após a aplicação em todos os tratamentos (Figura 4). Com o crescimento da planta há maior formação de área foliar o que facilita na absorção de água e nitrogênio, o que resulta no maior índice de verde na folha. Há vários trabalhos na literatura evidenciando a alta correlação entre os teores foliares de nitrogênio e os índices SPAD em várias culturas tais como café (REIS et al., 2015), trigo (WANG et al., 2016), arroz (YUAN et al., 2016), milho (ATTIA et al., 2015).

$$
\text { XIONG et al. (2015) }
$$

desenvolveram uma série de experimentos para estudar a resposta de várias culturas como arroz, milho, tomate, soja, amendoim e algodão a adubação nitrogenada utilizando o medidor portátil de clorofila. Os autores concluíram que os valores SPAD de clorofila foram altamente correlacionados com o teor foliar de nitrogênio. Contudo, os índices de clorofila podem ser influenciados por vários fatores como temperatura, irradiação, condições ambientais e espécie vegetal (monocotiledôneas e dicotiledôneas). No Brasil, ainda é necessário mais estudos relacionados ao uso do medidor portátil de clorofila para monitorar o estado nutricional das plantas sob diferentes condições ambientais e climáticas. 

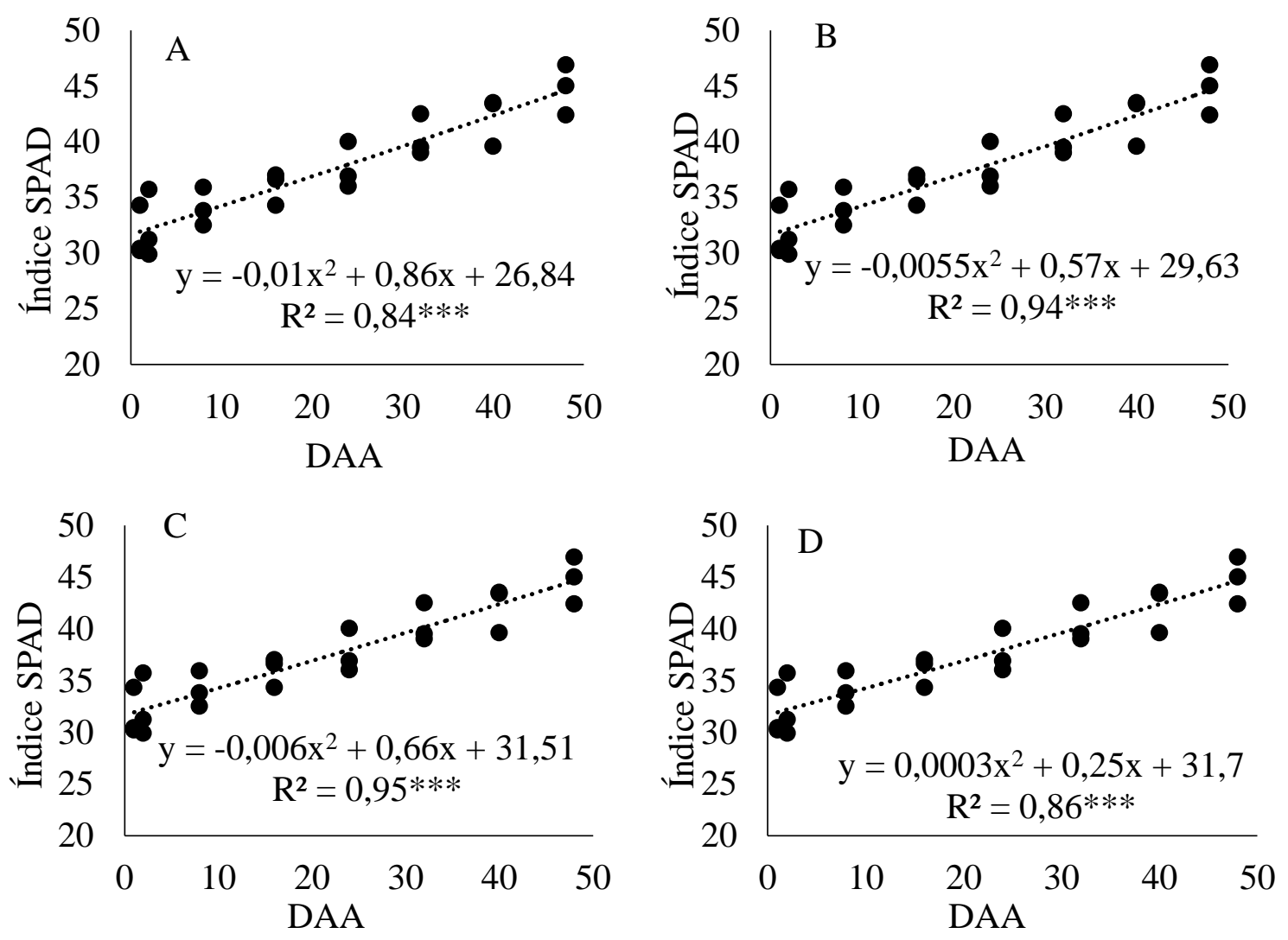

Figura 4. Índice SPAD para a cultura do algodão submetido em diferentes doses de nitrogênio. (A) dose 0 de N, (B) dose 40 de N, (C) dose 80 de $\mathrm{N}$ e (D) dose 120 de N.

\section{CONCLUSÕES}

O níquel não tem efeito no aumento no índice de clorofila. O intervalo entre 45 a $90 \mathrm{~kg} \mathrm{ha}{ }^{-1}$ de nitrogênio proporcionou maiores leituras SPAD. O índice de clorofila correlacionou-se positivamente com o teor de nitrogênio nas

\section{REFERÊNCIAS BIBLIOGRÁFICAS}

ATTIA, A.; SHAPIRO, C.; KRANZ, W.; MAMO, M; MAINZ, M. Improved yield and nitrogen use efficiency of corn following soybean in irrigated sandy loams. Soil Science Society of America Journal, v. 79: 1693-1703, 2015.

BRITO, G.G.; SOFIATTI, V.; BRANDÃO, Z.N.; SILVA, V.B.; SILVA, F.M.; Silva, D.A. Non-destructive analysis of photosynthetic pigments in cotton plants. Acta Scientiarum Agronomy, v. 33: 671-678, 2011.

CETIN, O.; UZEN, N.; TEMIZ, M.G. Effect of $\mathrm{N}$-fertigation Frequency on the folhas mas não com os teores foliares de níquel. A estimativa do teor de clorofila foi promissora para detecção de possíveis deficiências de nitrogênio e pode ser utilizado para manejo da adubação nitrogenada na cultura do algodão.

Lint Yield, Chlorophyll, and Photosynthesis Rate of Cotton. Journal of Agricultural Science and Technology, v. 17(4): 909-920, 2015.

EMPRESA BRASILEIRA DE PESQUISA AGROPECUÁRIA - EMBRAPA. Sistema brasileiro de classificação de solos. 2 ed. Rio de Janeiro: Brasília, p. 306, 2006.

FABIANO, C. C.; TEZOTTO, T.; FAVARIN, J.L.; POLACCO, J.C.; MAZZAFERA, P. Essentiality of nickel in plants: a role in plant stresses. Frontiers in Plant Science, v. 6: 754, 2015. 
FUNDAÇÃO MT. Cultivares convencionais: FMT 701. Disponível em: http://www.fundacaomt.com.br/algodao/?c ult $=$ fmt701. Acesso em: 20 de agosto de 2014.

MALAVOLTA, E.; VITTI, G.C.; OLIVEIRA, S.A. Avaliação do estado nutricional das plantas: princípios e perspectivas. 2.ed. Piracicaba: POTAFOS. p. 319, 1997.

MAO, L.; ZHANG, L.; EVERS, J.B.; WOPKE, W.; LIU, S.; ZHANG, S.; WANG, B.; LI, Z. Yield components and quality of intercropped cotton in response to mepiquat chloride and plant density. Field Crops Research, 179: 63-71, 2015.

MINOLTA CAMERA Co., Ltda. Manual for chlorophyll meter SPAD 502. Osaka, Minolta, Radiometric Instruments divisions. p. 22, 1989.

MOTOMIYA, A. V. A.; VALENTE, I. M. Q.; MOLIN, J. P.; MOTOMYIA, W. R.; BISCARO, G. A.; JORDAN, R. A. Índice de vegetação no algodeiro sob diferentes doses de nitrogênio e regulador de crescimento. Semina: Ciências Agrárias, Londrina, v. 35(1): 169-178, 2014.

POLACCO, J.C.; MAZZAFERA, P.; TEZOTTO, T. Opinion Nickel and urease in plants: Still many knowledge gaps. Plant Science, v. 199: 79-90, 2013.

RAIJ, B.V.; ANDRADE, J.C.; CANTARELLA, H.; QUAGGIO, J.A., eds. Análise química para avaliação da fertilidade de solos tropicais. Campinas, Instituto Agronômico, p.285, 2001.

REIS, A. R.; RODAK, B.W.; PUTTI, F.F.; MORAES, M.F. Papel fisiológico do níquel: essencialidade e toxidez em plantas. Piracicaba: Informações Agronômicas, IPNI, (147): 10-24, 2014.

REIS, A.R.; FAVARIN, J.L.; GRATÃO, P.L.; CAPALDI, F.R.; AZEVEDO, R.A. Antioxidant metabolism in coffee (Coffea arabica L.) plants in response to nitrogen supply. Theoretical and Experimental Plant Physiology, v. 27(3-4): 203-213, 2015.
RODAK, B. W. Níquel em solos e na cultura de soja. 2014. 101p. Dissertação Mestrado - Universidade Federal do Paraná, Curitiba, 2014.

ROSA, H.A.; SANTOS, R. F.; VIEIRA, M. C.; WERNER, J. M. D.; OLIVEIRA, M. R. Nitrogênio na cultura do Algodão. Acta Iguazu, Cascavel, v.1(1): 64-68, 2012

ROSOLEM, C. A.; VAN MELLIS, V. Monitoring nitrogen nutrition in cotton. Revista Brassileira de Ciências do Solo, v. 34, (5): 1601-1607, 2010.

SALEEM, M.F.; BILAL, M.F.; ANJUM, S.A.; RAZA, M.A.S.; MAQBOOL, M.; GHAFFARI, A. Effect of fruiting branch/square removal on growth and quality of bt cotton under different potassium rates. Communications in Soil Science and Plant Analysis, v. 47(2): 156-166, 2016.

STAMATIADIS, S.; TSADILAS, C.; SAMARAS, V.; SCHEPERS, J.S.; ESKRIDGE, K. Nitrogen uptake and Nuse efficiency of Mediterranean cotton under varied deficit irrigation and $\mathrm{N}$ fertilization. European Journal of Agronomy, v.73: 144-151, 2016.

TEZOTTO, T.; SOUZA, S.A.R.; MIHAIL, J.; FAVARIN, J.L.; MAZZAFERA, P.; BILYEU, K.; POLACCO, J.C. Deletion of the single UreG urease activation gene in soybean NIL lines: characterization and pleiotropic effects. Theoretical and Experimental Plant Physiology, v. 1: 116, 2016.

WANG, H.F.; HUO, Z.G.; ZHOU, G.S.; LIAO, Q.H.; FENG, H.K.; WU, L. Estimating leaf SPAD values of freezedamaged winter wheat using continuous wavelet analysis. Plant Physiology and Biochemistry, v. 98: 39-45, 2016.

YUAN, Z.F.; ATA-UL-KARIM, S.T.; CAO, Q.; LU, Z.Z.; CAO, W.X.; ZHU, Y.; LIU, X.J. Indicators for diagnosing nitrogen status of rice based on chlorophyll meter readings. Field Crops Research, v. 185: 12-20, 2016. 
XIONG, D.L.; CHEN, J.; YU, T.T.; GAO,

W.L; Ling, X.X.; Li, Y.; PENG, S.B.;

Huang, J.L. SPAD-based leaf nitrogen estimation is impacted by environmental factors and crop leaf characteristics.

Scientific Reports, v. 5: 1-12, 2015. 